\title{
In Vitro Evaluation of Beneficial Properties of Bacteriocinogenic Lactobacillus plantarum ST8Sh
}

\author{
Svetoslav Dimitrov Todorov ${ }^{1}$ - Wilhelm Holzapfel ${ }^{2} \cdot$ Luis Augusto Nero ${ }^{1}$
}

Published online: 10 December 2016

(C) Springer Science+Business Media New York 2016

\begin{abstract}
Lactobacillus plantarum ST8Sh, isolated from Bulgarian salami "shpek" and previously characterized as bacteriocin producer, was evaluated for its beneficial properties. Based on the PCR analysis, Lb. plantarum ST8Sh was shown to host a gene related to the production of adhesion proteins such as Mab, Mub, EF, and PrgB. Genetic and physiological tests suggest $L b$. plantarum ST8Sh to represent a potential probiotic candidate, including survival in the presence of low levels of $\mathrm{pH}$ and high levels of ox bile, production of $\beta$-galactosidase, bile salt deconjugation, high level of hydrophobicity, functional auto- and co-aggregation properties, and adhesion to cell lines. Application of semi-purified bacteriocin produced by $L b$. plantarum ST8Sh in combination with ciprofloxacin presented synergistic effect on inhibition of Listeria monocytogenes Scott A. Based on observed properties, $L b$. plantarum ST8Sh can be considered as a potential probiotic candidate with additional bacteriocinogenic properties.
\end{abstract}

Keywords Lactobacillus plantarum · Probiotics ·

Bacteriocins

\section{Introduction}

Lactic acid bacteria (LAB) have been actively studied in the last three decades as potential candidates for biopreservation

Svetoslav Dimitrov Todorov

slavi310570@abv.bg

1 Veterinary Department, Universidade Federal de Viçosa, Campus UFV, Viçosa 36570-900, Minas Gerais, Brazil

2 AGEE, Handong Global University, Pohang, South Korea processes and for their potential as probiotics. The concept of application of beneficial LAB in human health is not new. The idea of exploring the beneficial potential of LAB has been proposed and scientifically justified almost one century ago by Ilia Metchnikov and Stamen Grigorov. Since then, this group of bacteria has been the subject of numerous studies and patents. However, utilization of the LAB and their metabolites has been part of the human tradition and domestic practices since earliest history and in particular in the preparation of various fermented food products, some of which even having been traditionally appreciated as medicine [1-3]. In the second half of the twentieth century, a scientific basis of probiotic concepts was established. According to the World Health Organization/Food and Agricultural Organization (WHO/FAO) probiotics are "live microorganisms which when administered in adequate amounts confer a health benefit to the host" [4]. However, in 2009, according to the International Scientific Association for Probiotics and Prebiotics (ISAPP), the term probiotic is commonly misused in commercial products with frequently no scientific proof of benefits to human and animal health, while, moreover, the term has also been used to describe bacterial components, dead bacteria, or bacteria with uncharacterized health effects [5]. According to the $\mathrm{FAO} / \mathrm{WHO}$ definition, a probiotic must (i) be alive when administered at a specific level $\left(10^{6}\right.$ $10^{7} \mathrm{CFU}$ per gram of food product), (ii) have undergone controlled evaluation to document health benefits in the target host, (iii) be a taxonomically defined microbe or combination of microbes (specifying genus, species, and strain level); and (iv) be safe for its intended use [4, 6-9].

The role of bacteriocin production in relation to probiotic properties of LAB is very often misunderstood. It is important to underline that bacteriocin production is regarded as just a complimentary (not mandatory) beneficial feature of probiotic $\mathrm{LAB}$. If a probiotic $\mathrm{LAB}$ can produce bacteriocins, this may 
influence its chances for surviving harsh conditions in the gastrointestinal tract (GIT) by outcompeting other (closely related) microbial species present in the same environmental niche. In addition to competition with pathogenic bacteria and reduction of gastrointestinal infections, bacteriocinogenic LAB, like probiotics, can also confer additional health benefits to the host also by alleviation of processes such as inflammatory bowel disease, modulation of the immune system, and defense against recolonization by pathogenic microorganisms $[4,8,10]$.

Other beneficial features typical of a wide array of LAB correlate with desirable characteristics of potential probiotics, including aggregation properties, survival in the harsh upper GIT conditions such as low $\mathrm{pH}$ and presence of bile salts, adhesion ability to (human intestinal) cell lines, favorable interaction with commonly used non-antibiotic drugs, and survival (non-transferable resistance) against antibiotics. In addition, safety aspects of novel strains of putatively probiotic LAB need to be carefully examined and the potential of delivering virulence factors to host microbiota needs to be excluded.

Application of different Lactobacillus plantarum strains was intensively studied in prevention and control of various diseases [11-13]. Lb. plantarum strains have been applied for control of gastrointestinal disorders and specific control of Salmonella spp., Escherichia coli, and Clostridium difficile, restoration of the GIT microbial balance after antibiotic treatments and intestinal discomfort, treatment of constipation and diarrhea, enhancement of the GIT barrier function, inducing immune modulatory effects, treatment of chronic venous ulcers, control of inflammation of the GIT, reduction of allergic response, protection against influenza virus infection, maintenance of oral health, treatment of burns, prevention and treatment of cardiovascular disease, cholesterol reduction, and anti-obesity effects [11].

The aim of this work was to investigate some beneficial properties of $L b$. plantarum ST8Sh, a bacteriocinogenic strain previously isolated from Bulgarian salami "shpek" [14], in order to characterize its potential as a probiotic culture.

\section{Material and Methods}

\section{Strains and Media}

Lb. plantarum ST8Sh, a bacteriocinogenic strain isolated from Bulgarian salami shpek [14], and the test strains Listeria monocytogenes ATCC 7644, L. monocytogenes Scott A, Enterococcus faecalis ATCC 19443, and Lactobacillus sakei ATCC 15521 were cultured in de Man, Rogosa and Sharpe (MRS) broth in the case of LAB and brain-heart infusion (BHI) in the case of Listeria spp. (Difco, Detroit, MI, USA), at $30{ }^{\circ} \mathrm{C}$, and stored at $-80{ }^{\circ} \mathrm{C}$, in presence of $20 \%$ glycerol.
Screening for Probiotic Properties in Presence of Related Genes

Total DNA from $L b$. plantarum ST8Sh was isolated using the ZR Fungal/Bacterial DNA Kit (Zymo Research, Irvine, CA, USA) following the instructions of the manufacturer. Presence of genes related to adhesion properties of probiotic bacteria was investigated, using primers targeting $M u b$ (adhesion properties) (5'-GTA GTT ACT CAG TGA CGA TCAATG-3' and 5'-TAA TTG TAA AGG TAT AAT CGG AGG-3'), Map (adhesion properties) (5'-TGG ATT CTG CTT GAG GTA AG-3' and 5'-GAC TAG TAA TAA CGC GAC CG-3'), EFTu (adhesion properties) (5'-TTC TGG TCG TAT CGA TCG TG-3' and 5'-CCA CGT AAT AAC GCA CCA AC-3'), prgB (surface protein) (5'-GCC GTC GAC TCG AGG AGA ATG ATA CAT GAA T-3' and 5'-CCT GCG GCC GCG TCC TTC TTT TCG TCT TCA A-3'), EF2662-cbp (choline-binding protein) (5'-GGC GTC GAC CAC TTA AAC TGA TAG AGA GGA AT-3' and 5'-CGC GCC GCA ATT AAT TAT TAA CTA GTT TCC-3'), EF1249-fbp (fibrinogen-binding protein) (5'-GCG GTC GAC AAA CGA GGG ATT TAT TAT G-3' and 5'CTG GCG GCC GCG TTT AAT ACA ATT AGG AAG CAG A-3'), and EF2380-maz (membrane-associated zinc metalloprotease) (5'-GCG GTC GAC GAC ATC TAT GAA AAC AAT-3' and 5'-TCC GCG CCG CCT TAA ACT TTC TCC TT-3') as described by Todorov et al. [9], Kao et al. [15], and Fortina et al. [16].

\section{Hydrophobicity}

Cell surface hydrophobicity of $L b$. plantarum ST8Sh was evaluated on overnight stationary-phase culture. Bacterial culture was centrifuged at $7000 \times \mathrm{g}$ for $5 \mathrm{~min}$ at $4{ }^{\circ} \mathrm{C}$, and the cells were washed twice with phosphate buffer $\left(50 \mathrm{mM} \mathrm{K}_{2} \mathrm{HPO}_{4} /\right.$ $\left.\mathrm{KH}_{2} \mathrm{PO}_{4}, \mathrm{pH} 6.5\right)$ and resuspended in the same buffer until $A_{560}$ values $\left(A_{0}\right)$ near 1.0 were obtained. $N$-hexadecane was then added to the cell suspension (1:5), and the mixture was vortexed for $3 \mathrm{~min}$. The suspension was incubated for a period of $1 \mathrm{~h}$ at $37^{\circ} \mathrm{C}$, and the $A_{560}$ value $(A)$ of the aqueous layer was measured. Cell surface hydrophobicity was calculated according to the equation: $\% H=\left[\left(A_{0}-A\right) / A_{0}\right] \times 100$, where $A_{0}$ and $A$ are the absorbance values before and after extraction with the organic solvent, respectively. The assay was performed at three independent occasions in duplicates.

\section{Growth at Low pH and in Presence of Ox Bile}

Lb. plantarum ST8Sh was grown in MRS broth (Difco) adjusted to $\mathrm{pH} 3.0,4.0,5.0,6.0,7.0,9.0,11.0$, and 13.0 by adding $1 \mathrm{M} \mathrm{HCl}$ or $1 \mathrm{M} \mathrm{NaOH}$. In an additional experiment, Lb. plantarum ST8Sh was grown in MRS broth containing $0.2,0.4,0.6,0.8,1.0,2.0$, and $3.0 \%(w / v)$ of ox bile (Sigma). All tests were conducted in sterile flat-bottom 96-well 
microtiter plates (NUNC, Thermo Scientific). Each well was filled with $180 \mu \mathrm{L}$ of the bile-containing medium or MRS with modified $\mathrm{pH}$ and inoculated with $20 \mu \mathrm{L}$ of the $L b$. plantarum ST8Sh culture obtained in MRS broth (Difco) $\left(\mathrm{OD}_{600 \mathrm{~nm}}=0.2\right)$ at $37^{\circ} \mathrm{C}$. Changes in optical density readings were recorded at $600 \mathrm{~nm}$ every hour for $12 \mathrm{~h}$, using a microtiter plate reader (BioTek Instruments, Inc. USA). Cultures grown in MRS broth with $\mathrm{pH} 6.5$ and without bile served as control. Experiments were performed in triplicates.

\section{Aggregation and Co-aggregation}

For evaluation of auto-aggregation, Lb. plantarum ST8Sh was grown in MRS broth for $24 \mathrm{~h}$ at $37^{\circ} \mathrm{C}$. After harvesting by centrifugation $\left(7000 \times \mathrm{g}\right.$ for $10 \mathrm{~min}$ at $\left.20^{\circ} \mathrm{C}\right)$, the cells were washed twice, resuspended, and diluted in $0.85 \%$ sterile saline to reach approximate $\mathrm{OD}_{660 \mathrm{~nm}}=0.3$ (BEL Photonics, UV-vis Spectrophotometer, Italy) $\left(\mathrm{OD}_{0}\right)$. The cell suspension was incubated for $60 \mathrm{~min}$ at $37^{\circ} \mathrm{C}$. The $\mathrm{OD}_{660 \mathrm{~nm}}$ of the supernatant obtained after the cell suspension was centrifuged at $300 \times g$ for $2 \mathrm{~min}$ at $20^{\circ} \mathrm{C}$ was recorded, and auto-aggregation was determined using the following equation [17]: \% Autoaggregation $=\left[\left(\mathrm{OD}_{0}-\mathrm{OD}_{60}\right) / \mathrm{OD}_{0}\right] \times 100$, where $\mathrm{OD}_{0}$ refers to the initial $\mathrm{OD}$ and $\mathrm{OD}_{60}$ refers to the $\mathrm{OD}$ determined after $60 \mathrm{~min}$

For evaluation of co-aggregation, Lb. plantarum ST8Sh was grown in $10 \mathrm{~mL}$ MRS and L. monocytogenes Scott A and L. monocytogenes ATCC 7644, Lb. sakei ATCC 15521, and Enterococcus faecium ATCC 19433 in BHI or MRS, at $37{ }^{\circ} \mathrm{C}$. Cell suspensions were prepared as described before in the auto-aggregation test. The cell suspension of $L b$. plantarum ST8Sh was mixed with different co-aggregation partner's cell suspensions in equal volumes (1:1). The $\mathrm{OD}_{660 \mathrm{~nm}}$ was determined, and suspensions were incubated for $60 \mathrm{~min}$ at $37^{\circ} \mathrm{C} . \mathrm{OD}_{660 \mathrm{~nm}}$ of the supernatants obtained after the cell mixed culture suspensions were centrifuged at $300 \mathrm{~g}$ for $2 \mathrm{~min}$ at $20^{\circ} \mathrm{C}$ was recorded, and co-aggregation was determined using the following equation [17]: \% Coaggregation $=\left[\left(\mathrm{OD}_{\text {tot }}-\mathrm{OD}_{\mathrm{s}}\right) / \mathrm{OD}_{\text {tot }}\right] \times 100$, where $\mathrm{OD}_{\text {tot }}$ refers to the initial OD taken immediately after the tested strains were mixed while $\mathrm{OD}_{\mathrm{S}}$ refers to the $\mathrm{OD}$ of the supernatant after $60 \mathrm{~min}$. Experiments were conducted in triplicates at two separate occasions.

\section{$\beta$-Galactosidase Activity}

The $\beta$-galactosidase activity of $L b$. plantarum ST8Sh was assessed employing sterile filter paper disks impregnated with $o$-nitrophenyl- $\beta$-D-galactopyranose (ONPG disks, Fluka, Buchs, Switzerland), according to the manufacturer's instructions and as previously described by dos Santos et al. [18]. Overnight cultures of $L b$. plantarum ST8Sh were streaked on MRS agar plates and incubated anaerobically (GasPack
System, Oxoid, Basingstoke, Hampshire, UK) at $37{ }^{\circ} \mathrm{C}$ for $48 \mathrm{~h}$. A colony of $L b$. plantarum ST8Sh was picked and emulsified in a tube containing an ONPG disk soaked with $0.1 \mathrm{~mL}$ of sterile $0.85 \%(w / v)$ sodium chloride solution. The tubes were incubated at $35^{\circ} \mathrm{C}$ and checked at 1-h intervals for up to $6 \mathrm{~h}$. The release of a yellow chromogenic compound, $o$ nitrophenol, served as indication of a positive colony. The test was performed at two independent occasions in duplicates.

\section{Bile Salt Deconjugation}

In order to evaluate the ability of $L b$. plantarum ST8Sh to perform bile salt deconjugation, overnight cultures were streaked on MRS agar plates containing $0.5 \%(w / v)$ of the sodium salts of taurocholic acid (TC), taurodeoxycholic acid (TDC), glycocholic acid (GC), and glycodeoxycholic acid (GDC) (Sigma-Aldrich Co., St. Louis, USA). Lb. plantarum ST8Sh was incubated under anaerobic conditions (GasPack System, Oxoid) at $37{ }^{\circ} \mathrm{C}$ for $72 \mathrm{~h}$, and the presence of an opaque halo around colonies was considered positive for bile salt deconjugation. The test was performed according to dos Santos et al. [18] at two independent occasions in duplicates.

\section{Adhesion to Caco-2 Cell Line}

Caco-2 cells were grown in MEM, supplemented with $10 \%(v / v)$ fetal bovine serum (Sigma), $100 \mathrm{U} / \mathrm{mL}$ penicillin, and $100 \mathrm{U} / \mathrm{mL}$ streptomycin (Sigma) at $37{ }^{\circ} \mathrm{C}$. Caco-2 monolayers were prepared in 24-well tissue plates (Sigma) and inoculated with $1 \times 10^{5}$ cells per well to obtain confluence. The medium was changed every second day. The cells were washed twice with $1 \mathrm{~mL}$ sterile PBS. The medium was replaced by fresh nonsupplemented MEM, at least $1 \mathrm{~h}$ before the adhesion assay.

Lb. plantarum ST8Sh was inoculated in MEM, supplemented with $2 \%(v / v)$ fetal calf serum (Invitrogen, Eggenstein, Germany) for $24 \mathrm{~h}$ at $37^{\circ} \mathrm{C}$. Wells containing the Caco- 2 cell monolayers were inoculated with $100 \mu \mathrm{L}$ of each bacterial suspension (ca. $1 \times 10^{6} \mathrm{CFU} / \mathrm{mL}$ ) and the plates centrifuged at $300 \mathrm{~g}$ and $4{ }^{\circ} \mathrm{C}$ for $2 \mathrm{~min}$. The Caco- 2 cells were washed twice with $1 \mathrm{~mL}$ sterile PBS and then lysed by adding $1 \mathrm{~mL} 0.5 \%(v / v)$ Triton X-100. Appropriate dilutions for bacterial counts were plated onto MRS agar. Adhesion of bacterial cells to Caco-2 cells was calculated from the initial number of viable cells, number of cells in the supernatant, and number of cells in the lysate after treatment with Triton $\mathrm{X}-100$. Lactobacillus rhamnosus GG was used as positive control of adherence to Caco-2 cells. Experiments were done in triplicate.

\section{Bacteriocin Test}

Lb. plantarum ST8Sh was grown on MRS at $37^{\circ} \mathrm{C}$ for $24 \mathrm{~h}$, and cell-free supernatant was obtained by centrifugation at 
$10,000 \mathrm{~g}$ for $10 \mathrm{~min}$. The $\mathrm{pH}$ of the supernatant was adjusted to 6.0-6.5 with $1 \mathrm{M} \mathrm{NaOH}$ and treated for $10 \mathrm{~min}$ at $80^{\circ} \mathrm{C}$. Ten microliters of the cell-free supernatant was spotted onto the surface of BHI with $0.7 \%$ agar containing $10^{5} \mathrm{CFU}$ of L. monocytogenes Scott A per milliliter. The plates were incubated at $37{ }^{\circ} \mathrm{C}$ for $24 \mathrm{~h}$ and checked for the presence of inhibitory zones. Those generated inhibition zones larger than $2 \mathrm{~mm}$ in diameter were considered as positive.

Titer of the expressed bacteriocin was determined as described by dos Santos et al. [18]. The obtained cell-free supernatant was serially diluted $2 \times$ in $100 \mathrm{mM}$ phosphate buffer pH 6.5 and $10 \mu \mathrm{L}$ from each dilution spotted on the surface of BHI with $0.7 \%$ agar agar with $10^{5} \mathrm{CFU} / \mathrm{mL}$ final concentration of L. monocytogenes Scott A. The highest dilution resulting in an inhibition zone larger than $2 \mathrm{~mm}$ was considered as basis for the calculation of arbitrary units per milliliter, taking into consideration the volume of the deposited material and level of dilution.

\section{Bacteriocin Production and Partial Purification}

Lb. plantarum ST8Sh was cultured in MRS broth at $37^{\circ} \mathrm{C}$ for $24 \mathrm{~h}$. Cell-free supernatant was obtained as described before. Bacteriocin was precipitated by addition of ammonium sulfate to the cell-free supernatant to obtain $60 \%$ saturation and stirred for $4 \mathrm{~h}$ at $4{ }^{\circ} \mathrm{C}$. After centrifugation for $1 \mathrm{~h}$ at $12,000 \mathrm{~g}$ at $4{ }^{\circ} \mathrm{C}$, the resulting pellet was resuspended in $100 \mathrm{~mL}$ of $25 \mathrm{mM}$ ammonium acetate buffer $(\mathrm{pH}$ 6.5) and loaded on a Sep-Pak $\mathrm{C}_{18}$ cartridge (Waters, Millipore, MA, USA), and bacteriocin was eluted with 60 and $80 \%$ isopropanol in $25 \mathrm{mM}$ ammonium acetate buffer ( $\mathrm{pH}$ 6.5). The active fraction was dried under vacuum (Speed-Vac, Savant, France), and the bacteriocin fraction was resuspended in sterile distilled water and filtered using 0.22- $\mu \mathrm{m}$-pore-size filter units (Waters).

\section{Synergistic Interaction Between Bacteriocin and Antibiotic (Ciprofloxacin)}

In the first experiment, the minimal inhibition concentration of ciprofloxacin (Sigma) was determined by growing L. monocytogenes Scott A in BHI, supplemented with antibiotic concentrations varying from 1.25 to $640 \mu \mathrm{g} / \mathrm{mL}$. In a subsequent experiment, the combined effect of ciprofloxacin and semi-purified bacteriocin (60\% iso-propanol fraction) produced by ST8Sh was determined. All tests were conducted in sterile flat-bottom microtiter plates (NUNC, Thermo Scientific). Each well was filled with $190 \mu \mathrm{L}$ of sterile BHI medium adjusted to $\mathrm{pH} 6.0$ with $1 \mathrm{M}$ lactic acid, supplemented with final concentrations of 320, 160, 80, 40, 20, 10 and $5 \mu \mathrm{g} / \mathrm{mL}$ ciprofloxacin from left to right of the microtiter plates and final bacteriocin concentrations of 51,200; 12,$800 ; 3200 ; 800 ; 200 ; 50 ; 12.5 ; 3.12 ; 0.78$; and $0.20 \mathrm{AU} /$
$\mathrm{mL}$ from top to bottom of the plates. Each well was inoculated with $10 \mu \mathrm{L}$ L. monocytogenes Scott A (OD $600 \mathrm{~nm}=0.2)$. Optical density readings (at $655 \mathrm{~nm}$ ) were recorded every hour for $30 \mathrm{~h}$ on a microplate reader (BioTek Instruments, Inc. USA). Cultures grown in BHI broth (Difco) without added bacteriocins and ciprofloxacin served as control.

\section{Results}

\section{Screening for Probiotic Properties in Presence of Related Genes}

In the present study, our focus was on further beneficial properties of this strain for which we have designed an experimental approach for evaluating its probiotic potential. Based on the performed PCR analysis, the presence of Map, Mub, EfTu, EF2662-cbp, and EF2380-maz was detected in the genome of $\mathrm{Lb}$. plantarum ST8Sh, while the presence of $\mathrm{prgB}$ and EF1249-fbp could not be confirmed.

\section{Hydrophobicity}

In addition to the presence of specific proteins, related to binding capacity of probiotic bacteria, the hydrophobic nature of the external surface of microorganisms can have an essential role in the attachment of bacteria to the host tissue. The average hydrophobicity value registered for $L b$. plantarum ST8Sh was $52 \%$.

\section{Growth at Low pH and in Presence of Ox Bile}

Growth and survival in the presence of low levels of $\mathrm{pH}$ and presence of ox bile are required characteristics for the future probiotic strains and normally are one of the initial tests in prescreening test for the selection of beneficial LAB. The obtained results indicate that $L b$. plantarum ST8Sh can grew well in MRS broth with initial pH values of 5.0-9.0 (Fig. 1a), but at $\mathrm{pH} 4.0$, the growth rate was much lower. Even if intensive bacterial growth of $L b$. plantarum ST8Sh was not recorded, the cells were viable, and when plated on MRS agar, they show good survival (data not shown). In addition, $L b$. plantarum ST8Sh presented good growth in the presence of ox bile at concentrations ranging from 0.2 to $3.0 \%$ (Fig. 1b), suggesting that this strain has good chances to survive in the human GIT.

\section{Aggregation properties}

Lb. plantarum ST8Sh was characterized as having an autoaggregation level of $51.32 \%$; however, auto-aggregations for L. monocytogenes Scott A, L. monocytogenes ATCC 7644, Lb. sakei ATCC 15521, and E. faecium ATCC 19433 were 
Fig. 1 a Comparison of growth of Lactobacillus plantarum ST8Sh in MRS broth (Difco) at different $\mathrm{pH}$ levels. Each result represents an average of three readings. $\mathbf{b}$ Comparison of growth of Lactobacillus plantarum ST8Sh in MRS broth (Difco) supplemented with different concentrations of ox bile. Each result represents an average of three readings a

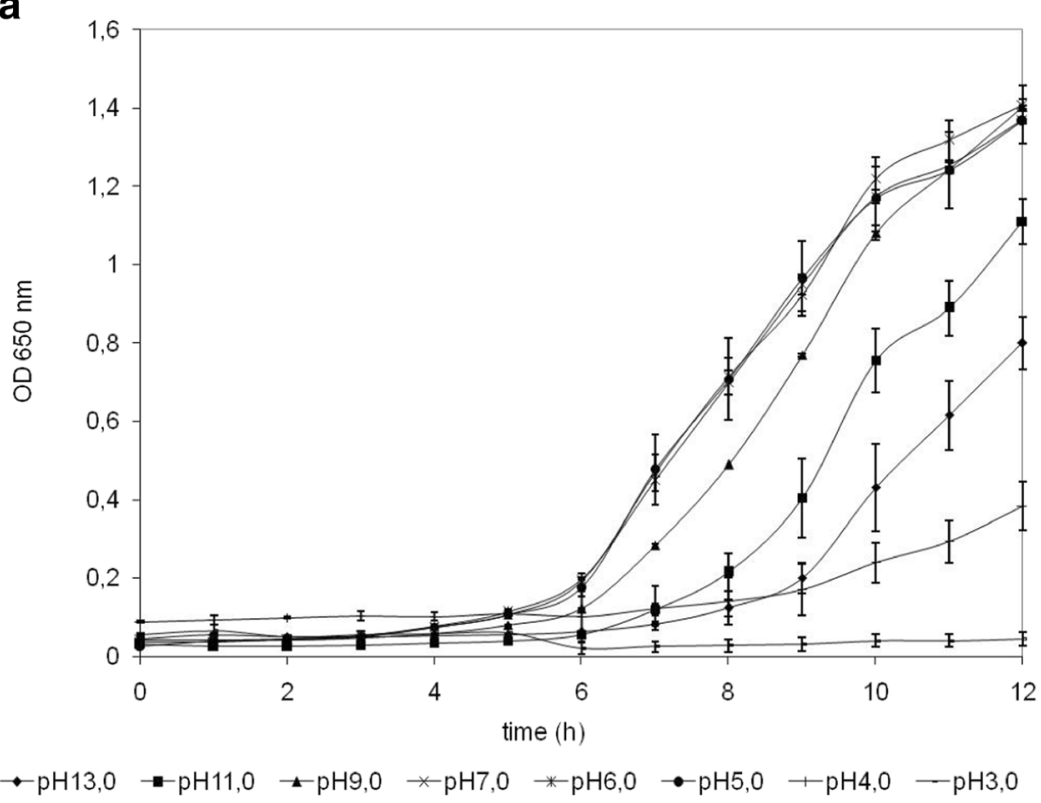

b

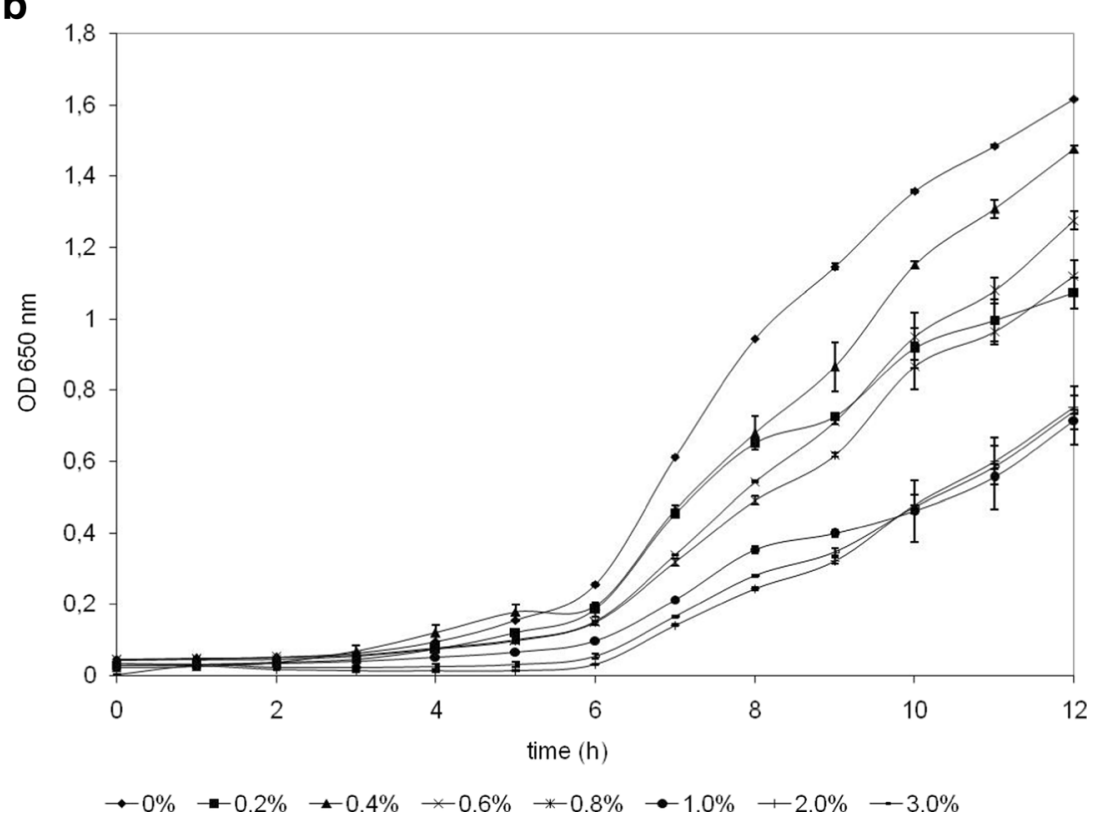

$29.65,32.74,44.86$, and $33.42 \%$, respectively (Fig. 2). The co-aggregations of $L b$. plantarum ST8Sh with L. monocytogenes Scott A, L. monocytogenes ATCC 7644, Lb. sakei ATCC 15521, and E. faecium ATCC 19433 were $28.54,31.96,39.43$, and $31.54 \%$, respectively, and also varied according to the strain (Fig. 2).

\section{$\beta$-Galactosidase Activity, Bile Salt Deconjugation, and Adhesion to Caco-2 Cell Line}

The production of $\beta$-galactosidase was detected for $L b$. plantarum ST8Sh throughout the qualitative in vitro test applying sterile filter paper disks impregnated with ONPG. Lb. plantarum ST8Sh was able to grow in the presence of $0.5 \%(w / v)$ of GDC, GC, TDC, and TC sodium salts. Adherence of $L b$. plantarum to Caco-2 cells was estimated to be $12.8 \%$, similar to that recorded for the reference strain, Lb. rhamnosus GG (10.9\%) (data not shown).

\section{Bacteriocin Test}

Bacteriocin produced by $L b$. plantarum ST8Sh was semipurified by ammonium sulfate precipitation and hydrophobic chromatography on a Sep-Pak $\mathrm{C}_{18}$ column. Semi-purified 
Fig. 2 Aggregation of Lactobacillus plantarum ST8Sh, Enterococcus faecalis ATCC 19443, Lactobacillus sakei ATCC 15521, Listeria monocytogenes ATCC 7644, and Listeria monocytogenes Scott A. Each result represents an average of three experiments

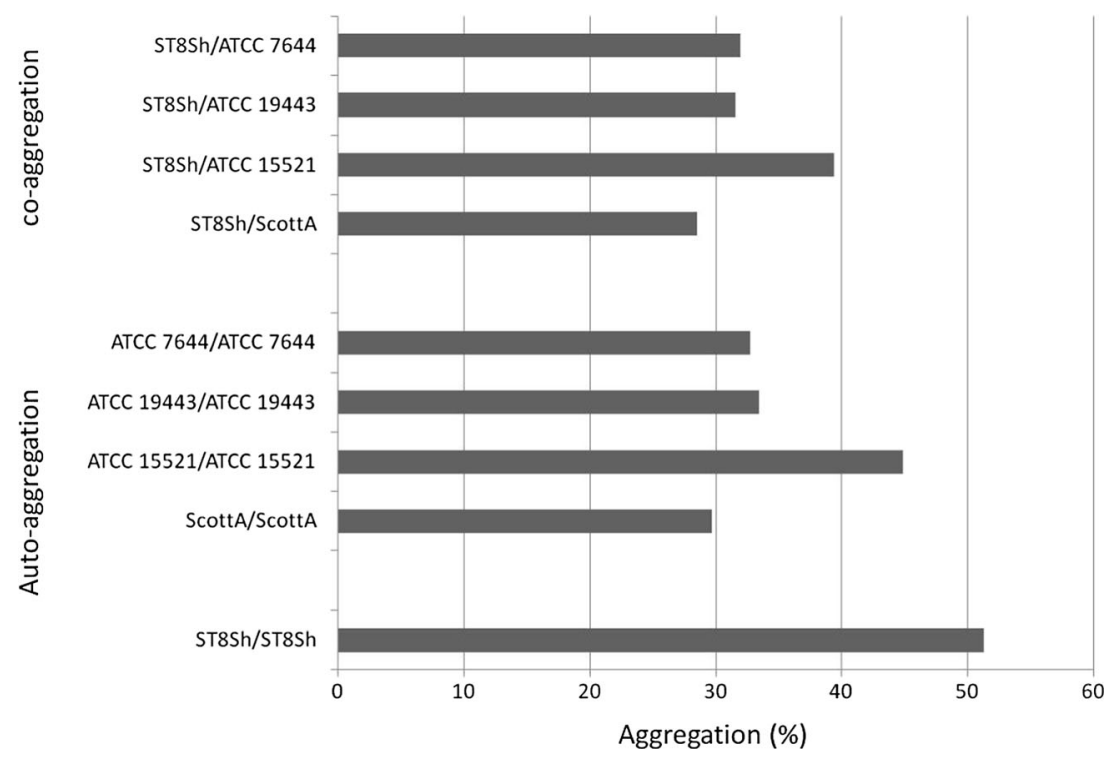

bacteriocin was presenting a very high activity against Listeria monocytogenes $(102,400 \mathrm{AU} / \mathrm{mL})$ and E. faecalis $(102,400 \mathrm{AU} / \mathrm{mL})$. Semi-purified fractions (60\% isopropanol) of bacteriocin ST8Sh were used in the following experiments.

\section{Synergistic Interaction Between Bacteriocin and Antibiotic (Ciprofloxacin)}

The minimal inhibition concentration (MIC) of ciprofloxacin for L. monocytogenes Scott A was determined as $80 \mu \mathrm{g} / \mathrm{mL}$. Based on the combined application of ciprofloxacin and bacteriocin produced by $L b$. plantarum ST8Sh, antibacterial activity strongly increased when sublethal levels of ciprofloxacin were used in combination with the studied bacteriocins (Fig. 3). Based on the observed results, ciprofloxacin levels below MIC (e.g., $40 \mu \mathrm{g} / \mathrm{mL}$ ) may thus be used when administered in combination with bacteriocins produced by $L b$. plantarum ST8Sh. Growth inhibition of L. monocytogenes Scott A was recorded during the first $10 \mathrm{~h}$ and continued for the duration of the experiment. However, cells of L. monocytogenes Scott A treated with either bacteriocins produced by $L b$. plantarum ST8Sh or ciprofloxacin developed resistance after $24 \mathrm{~h}$ and can be observed after $30 \mathrm{~h}$ as well.

\section{Discussion}

In a previous study [14], we reported on the isolation of $L b$. plantarum ST8Sh from Bulgarian salami shpek and characterization of its bacteriocin with special focus on its mode of action against L. monocytogenes Scott $\mathrm{A}$ and $E$. faecalis ATCC 19433. Considering the antimicrobial activity of bacteriocin ST8Sh against the test microorganisms and the specific physiological characteristics of $L b$. plantarum ST8Sh, we have suggested in our previous study that either the bacteriocin or the strain may be used in biopreservation [14]. However, in the present study, our focus was on further beneficial properties of this strain for which we have designed an experimental approach for evaluating its probiotic potential.

Genes related to encoding different adhesion proteins $M u b$, Map, EFTu, $\operatorname{prgB}, E F 2662$-cbp, EF1249-fbp, and EF2380maz $[9,15,16]$ were targeted by PCR analysis in total DNA from $L b$. plantarum ST8Sh. The presence of Map, Mub, EfTu, EF2662-cbp, and EF2380-maz was detected in the genome of $L b$. plantarum ST8Sh, while the presence of prgB and EF1249-fbp could not be confirmed. The mub gene encodes extracellular mucus-binding proteins (MUBs), frequently found in intestinal lactobacilli and especially in $L b$. plantarum $[17,19,20]$. A similar profile was reported for the presence of the map gene, associated with the production of a mucus adhesion-promoting protein (MapA). Its mechanism of action, however, has not been fully determined yet [21]. Elongation factor $\mathrm{Tu}(\mathrm{EF}-\mathrm{Tu})$ is a multifunctional protein produced by certain lactobacilli, including $L b$. plantarum $[19,20]$, that can also mediate adhesion and facilitate the colonization of human intestinal mucus. The importance of the $\operatorname{prgB}$ gene for adhesion of surface proteins was studied by Kao et al. [15]. Although the presence of the studied genes in the genome of probiotic candidates is recommended, it is not considered an essential characteristic in the screening of new potentially beneficial strains. These genes will provide an advantage to potential probiotics in the adhesion process to intestinal cells; however, the expression of these genes is a complex process and can be regulated and limited by several factors. The capacity of probiotic bacteria to adhere to the intestinal mucosa is a relevant 

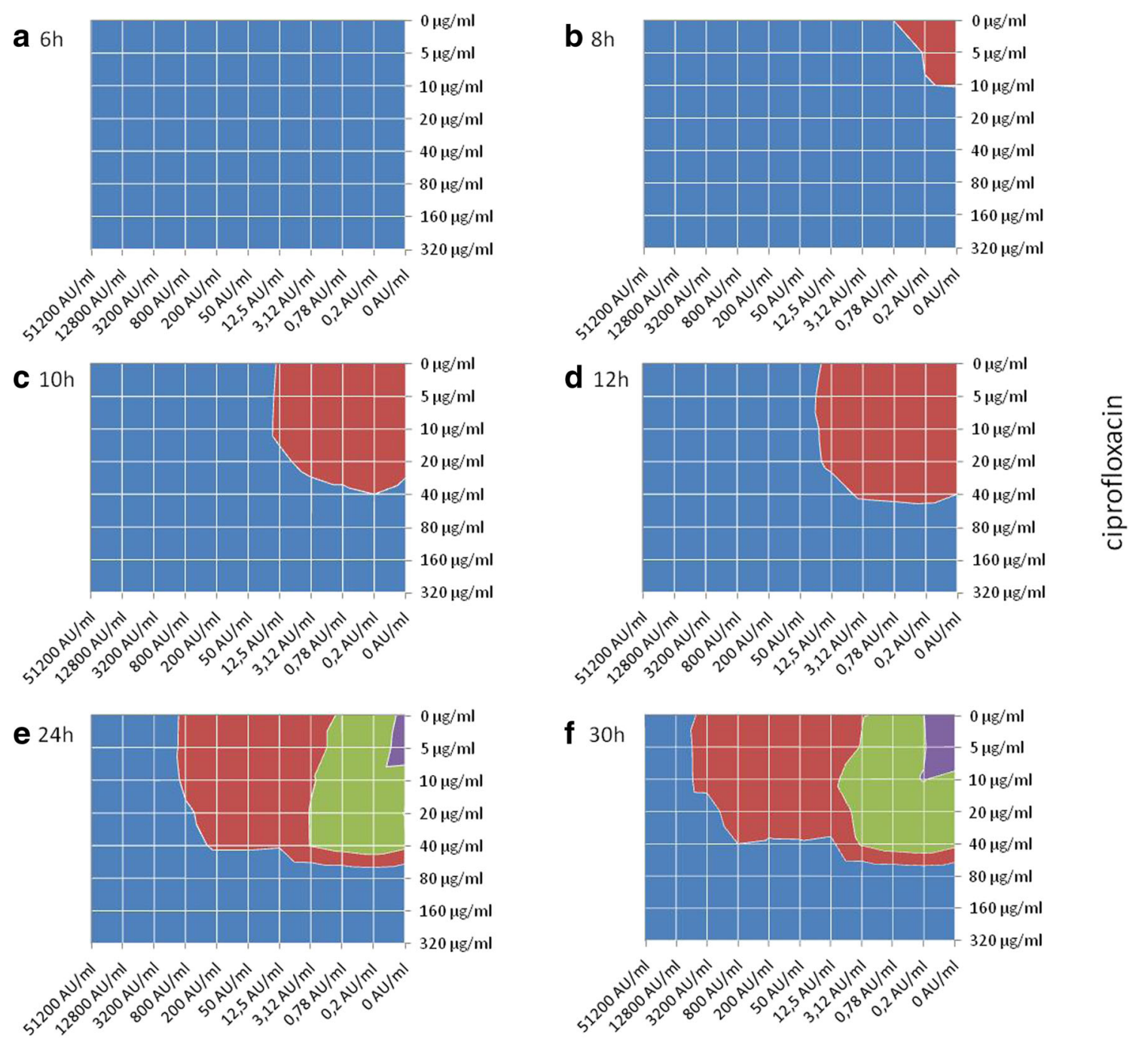

\section{Bacteriocin ST8Sh}

Growth of Listeria monocytogenes Scott A detected at $650 \mathrm{~nm}$

$$
\square-0,2=0,2-0,4=0,4-0,6 \quad 0,6-0,8
$$

Fig. 3 Inhibitory effect on Listeria monocytogenes Scott A by combined effect of bacteriocin produced by Lactobacillus plantarum ST8Sh (from 51,200 to $0.2 \mathrm{AU} / \mathrm{mL}$ ) and ciprofloxacin (from 320 to $5 \mu \mathrm{g} / \mathrm{mL}$ ) at $37^{\circ} \mathrm{C}$ after $6,8,10,12,24$, and $30 \mathrm{~h}$

characteristic related to consistency of beneficial properties and effects related to the modulation of the immune system and to competitive exclusion of pathogens [22,23]. Several studies have shown surface proteins with mucus-binding capacity to mediate the adherence of lactobacilli to the intestine $[24,25]$. However, various mechanisms may be involved in this process [26, 27].

In addition to the presence of specific proteins, related to binding capacity of probiotic bacteria, the hydrophobic nature of the external surface of microorganisms can have an essential role in the attachment of bacteria to the host tissue. Related to this, the cellular surface hydrophobicity has been recommended as a test, used to estimate the ability of the strain to adhere to epithelial cells [27]. The average hydrophobicity value registered for $L b$. plantarum ST8Sh was $52 \%$.
Vinderola et al. [27] consider values higher than $40 \%$ as elevated hydrophobicity, while Zago et al. [28] consider $30 \%$ as the cutoff value for high hydrophobicity. Based on these evidences, Lb. plantarum ST8Sh can be considered as a strain with high cell surface hydrophobicity. In addition, similar results related to hydrophobicity profile of different $L b$. plantarum strains was previously reported $[9,17]$.

Growth and survival in the presence of low levels of $\mathrm{pH}$ and presence of ox bile are required characteristics for the future probiotic strains and normally is one of the initial tests in prescreening test for the selection of beneficial LAB. To be able to perform any beneficial properties in the GIT, future probiotics need to survive via low $\mathrm{pH}$ in stomach and to be resistant to the presence of ox bile in the intestine. In order to protect $\mathrm{LAB}$ from the low $\mathrm{pH}$ during passage in stomach, 
some authors recommend encapsulation of probiotic LAB [29-31]. However, any additional protection and/or treatment of $\mathrm{LAB}$ can be related to the increase of the cost and to the reduction of viability of the probiotics.

The obtained results indicate that $L b$. plantarum ST8Sh can grew well in MRS broth with initial $\mathrm{pH}$ values of 5.0-9.0 (Fig. 1a), but at $\mathrm{pH} 4.0$, the growth rate was much lower. Even if intensive bacterial growth of Lb. plantarum ST8Sh was not recorded, the cells were viable, and when plated on MRS agar, they show good survival (data not shown). Different strains from Lactobacillus genus were shown to be able to grow and survive in the presence of low levels of $\mathrm{pH}$. Strains of $L b$. plantarum, $L b$. rhamnosus, Lb. pentosus, and $L b$. paracasei were previously reported as suppressed at $\mathrm{pH} 3.0$ and 4.0, and variable results were recorded for $\mathrm{pH}$ of 11.0 and 13.0 [32].

Lb. plantarum ST8Sh presented good growth in the presence of ox bile at concentrations ranging from 0.2 to $3.0 \%$ (Fig. 1b), suggesting that this strain has good chances to survive in the human GIT. However, bile salts have different effects in different Lactobacillus strains. The growth of the selected strains of $L b$. plantarum, $L b$. rhamnosus, and $L b$. pentosus was less affected by the presence of ox bile, compared to the strains of $L b$. paracase $i$ and $L b$. rhamnosus [32]. Similar effects of ox bile and $\mathrm{pH}$ on $L b$. plantarum $423, L b$. salivarius 241, and Lb. curvatus DF38 were reported by Brink et al. [33]. However, Haller et al. [34], reported that as many as $10 \%$ of $L b$. plantarum cells, but less than $0.001 \%$ of $L b$. sakei and $L b$. paracasei cells, survived when exposed to $\mathrm{HCl}$ (pH 2.0) and bile salts.

Adhesion is considered as one of the primary requirements for the probiotic potential of bacteria. Several mechanisms are involved in this process, including production and expression of adhesion proteins and polysaccharides. However, aggregation plays an important role in this process and needs to be assessed as an important feature for adhesion and biofilm formation. Lb. plantarum has been studied intensively, and a number of encoding genes were described related to surface proteins responsible for recognition of or binding to components present in the environment. Some of these genes are homologous to proteins with predicted functions, such as mucus binding, aggregation promotion, and intracellular adhesion [35]. Aggregation properties can be considered as positive or negative related to the bacteriocin spectrum of activity of the investigated strain. If the bacteriocin produced by $L b$. plantarum ST8Sh does not inhibit the co-aggregation partner, the two strains can co-exist and facilitate biofilm formation and may facilitate the colonization of the host with pathogenic bacteria. However, if the bacteriocin is active against the coaggregation partner, high co-aggregation will facilitate interbacterial contact and the bactericidal mode of action of bacteriocins against co-aggregating partner, allowing better elimination of the co-aggregation partner from the system. Based on a previous study, auto-aggregation is a strain- specific trait [17]. Lb. plantarum ST8Sh was characterized as having an auto-aggregation level of $51.32 \%$ (Fig. 2), which is lower than the levels reported by Todorov et al. [32] for other lactobacilli: $L b$. pentosus ST712BZ (67\%) and $L b$. paracasei ST284BZ (99\%). The co-aggregations of $L b$. plantarum ST8Sh with L. monocytogenes Scott A, L. monocytogenes ATCC 7644, Lb. sakei ATCC 1552, and E. faecium ATCC 19433 were 29.65, 32.74, 44.86, and $33.42 \%$, respectively, and also varied according to the strain (Fig. 2), but the lowest levels were observed for Listeria and Enterococcus strains. Low levels of co-aggregation may play an important role in preventing the formation of biofilms and preventing the persistence of pathogenic species in the GIT.

The production of $\beta$-galactosidase was detected for $L b$. plantarum ST8Sh throughout the qualitative in vitro test applying sterile filter paper disks impregnated with ONPG. The production of $\beta$-galactosidase by probiotic $\mathrm{LAB}$, including Lb. plantarum ST8Sh, can contribute to the alleviation of the symptoms of lactose intolerance due to lactase deficiency [36], which includes intestinal distress, excessive flatulence, or diarrhea, and is highly prevalent among some human groups [37].

Lb. plantarum ST8Sh was able to grow in the presence of $0.5 \%(w / v)$ of GDC, GC, TDC, and TC sodium salts. The ability to survive in the presence of bile is a desirable feature for probiotic bacteria, as it favors their viability at the intestinal part and is being recommended in the selection of new probiotic candidates $[27,38]$. The ability of LAB to deconjugate bile salts is a related feature to $\mathrm{LAB}$, important in reducing the toxicity of these compounds [39]. The role of LAB, involved in the deconjugation of bile salts, is related to the formation of bile acids that are less soluble and less absorbed from the intestinal lumen, and the deconjugation of bile salts favors their excretion via feces, which may imply the lowering of serum cholesterol levels to the host. This feature has been reported by Jones et al. [40], showing the cholesterollowering effect in vivo of a bile salt hydrolase-active Lactobacillus reuteri strain, in a double-blind, placebocontrolled clinical trial.

Adherence of $L b$. plantarum to Caco- 2 cells was estimated to be $12.8 \%$, similar to that recorded for the reference strain, Lb. rhamnosus GG (10.9\%). Other studies had also evaluated the binding of LAB to colon carcinoma cells. Todorov et al. [41] reported on adherence of different LAB isolated from smoked salmon to Caco-2 cells to be from 7.8 to $13.9 \%$. In other studies, Todorov et al. [32, 42] evaluated LAB isolated from boza and observed that adherence of studied LAB to Caco- 2 cells was in similar manner (0.26-9.0\%), in comparison to the 3.2 to $14.4 \%$ adhesion values reported by Tuomola and Salminen [43] (1998) and the 0.08 to $0.74 \%$ values reported by Bertazoni-Minelli et al. [7].

Based on the combined application of ciprofloxacin and bacteriocin produced by $L b$. plantarum ST8Sh, antibacterial 
activity strongly increased when sublethal levels of ciprofloxacin were used in combination with the studied bacteriocins (Fig. 3). Based on the observed results, ciprofloxacin levels below MIC (e.g., $40 \mu \mathrm{g} / \mathrm{mL}$ ) may thus be used when administered in combination with bacteriocins produced by $L b$. plantarum ST8Sh. Growth inhibition of L. monocytogenes Scott A was recorded during the first $10 \mathrm{~h}$ and continued for the duration of the experiment. However, cells of L. monocytogenes Scott A treated with either bacteriocins produced by $L$ b. plantarum ST8Sh or ciprofloxacin developed resistance after $24 \mathrm{~h}$ and can be observed after $30 \mathrm{~h}$ as well. Most probably, the bacteriocin produced by $L b$. plantarum ST8Sh was degraded by proteolytic enzymes produced by L. monocytogenes Scott A or was inactivated due to aggregation or adhesion processes.

Previously, a synergistic effect after combined application of ciprofloxacin and bacteriocin ST44AM, produced by Pediococcus pentosaceus on inhibition of Listeria ivanovii subsp. ivanovii ATCC 19119, was reported by Todorov and Dicks [44]. In a similar study, the effect of sublethal concentrations of enterocin CRL35, a cationic peptide, on the activity of erythromycin, chloramphenicol, and tetracycline was reported at sublethal concentrations and little growth inhibition was recorded [45]. Most probably, this synergistic effect can be explained as a result of the fact that Listeria spp. membrane depolarization is necessary, but not sufficient to produce cell death, and another concentration-dependent step, not described at present, may be implicated. Pleurocidin and derivatives, which are antimicrobial peptides from eukaryotic organisms, lost their ability to damage cell membranes at sublethal concentrations, while maintaining their capacities to inhibit macromolecular synthesis [46].

\section{Conclusions}

In our previous study, we have reported on bacteriocinogenic potential of $L b$. plantarum ST8Sh isolated from Bulgarian salami shpek. In the present study, we evaluated the basic characteristics required for a probiotic potential of this strain based on its functional behavior. In addition, combined application of expressed bacteriocin by Lb. plantarum ST8Sh and ciprofloxacin on inhibition of $L$. monocytogenes Scott A was evaluated and a synergistic effect between the two applied antimicrobials was observed. What will be the future of $L b$. plantarum ST8Sh? To be validated as a functional probiotic strain, additional research needs to be performed on its effect on immune system and observation on interaction with healthier and pathological human cells. Safety aspects of $L b$. plantarum ST8Sh need to be investigated, including possible presence of virulence factors, interaction of the strain itself with non-antibiotic drugs, resistance to antibiotics, and cytotoxicity of the expressed bacteriocins. However, this will be a part of the future studies.

Acknowledgements This work has been supported by research and personal grants from FAPEMIG (Belo Horizonte, MG, Brazil), CAPES (Brasilia, DF, Brazil), and CNPq (Brasilia, DF, Brazil).

\section{Compliance with Ethical Standards}

Conflict of Interest The authors declare that they have no conflict of interest.

\section{References}

1. Farnworth ER (2008) Handbook of fermented functional foods. CRC Press, Boca Raton ISBN 9781420053265

2. Mathara MJ, Schillinger U, Kutima PM, Mbugua KS, Holzapfel WH (2004) Isolation, identification and characterisation of the dominant microorganisms of kule naoto: the Maasai traditional fermented milk in Kenya. Int J Food Microbiol 94:269-278

3. Selhub EM, Logan AC, Bested AC (2014) Fermented foods, microbiota, and mental health: ancient practice meets nutritional psychiatry. J Physiolog Anthropol 33:2 http://www.jphysiolanthropol. com/content $/ 33 / 1 / 2$

4. FAO/WHO (2001) Report of a Joint FAO/WHO Expert Consultation on evaluation of health and nutritional properties of probiotics in food including powder milk with live lactic acid bacteria. Cordoba, Argenina, 1-4 October 2001; http://www.fao.org/3 /a-a0512e.pdf

5. ISAPP. Clarification of the definition of a probiotic of the International Scientific Association for Probiotics and Prebiotics [online]; 2009; [cited 2016 March 31]; Available from: http://www.isapp.net/Portals/0 /docs/ProbioticDefinitionClarification.pdf

6. LeBlanc JG, Todorov SD, de LeBlanc AM (2015) Beneficial effects of microorganisms isolated from papaya. In: Todorov SD, Ivanova IV (eds) Tropical fruits - from cultivation to consumption and health benefits: papaya. Nova Publisher, New York, pp. 105118

7. Bertazzoni-Minelli E, Benini A, Marzotto M, Sbarbati A, Ruzzenente O, Ferrario R, Hendriks H, Dellaglio F (2004) Assessment of novel probiotic Lactobacillus casei strains for the production of functional foods. Int Dairy J 14:723-736

8. Oelschlaeger TA (2010) Mechanisms of probiotic actions - a review. Int J Med Microbiol 300:57-62

9. Todorov SD, LeBlanc JG, Franco BDGM (2012) Evaluation of the probiotic potential and effect of encapsulation on survival for Lactobacillus plantarum ST16Pa isolated from papaya. World J Microbiol Biotechnol 28:973-984

10. Galdeano C, de Moreno A, Vinderola G, Bibas Bonet ME, Perdigón G (2007) A proposal model: mechanisms of immunomodulation induced by probiotic bacteria. Review. Clin Vacc Immunol 14:485-492

11. Martinez RCR, Vieira ADS, Santos KMO, Franco BDGM, Todorov SD (2012) Characterization and evaluation of Lactobacillus plantarum probiotic potential. In: Campos AIP, Mena AL (eds) Lactobacillus: classification, uses and health implications, Bacteriology research developments/microbiology research advances series. Nova Publisher, New York, pp. 36-63

12. Rao RK, Samak G (2013) Protection and restitution of gut barrier by probiotics: nutritional and clinical implications. Curr Nutr Food Sci 9:99-107 
13. Kelly JR, Kennedy PJ, Cryan JF, Dinan TG, Clarke G, Hyland NP (2015) Breaking down the barriers: the gut microbiome, intestinal permeability and stress-related psychiatric disorders. Front Cell Neurosci. doi:10.3389/fncel.2015.00392

14. Todorov SD, Holzapfel W, Nero LA (2016) Characterization of a novel bacteriocin produced by Lactobacillus plantarum ST8SH and some aspects of its mode of action. Ann Microbiol 66:949-962

15. Kao S-M, Olmsted SB, Viksnins AS, Gallo JC, Dunny GM (1991) Molecular and genetic analysis of a region of plasmid pCF10 containing positive control genes and structural genes encoding surface proteins involved in pheromone-inducible conjugation in Enterococcus faecalis. J Bacteriol 173:7650-7664

16. Fortina MG, Ricci G, Borgo F, Manachini PL, Arends K, Schiwon K, Abajy MY, Grohmann E (2008) A survey on biotechnological potential and safety of the novel Enterococcus species of dairy origin, E. italicus. Int J Food Microbiol 123:204-211

17. Todorov SD, Dicks LMT (2008) Evaluation of lactic acid bacteria from kefir, molasses and olive brine as possible probiotics based on physiological properties. Ann Microbiol 58:661-670

18. dos Santos KMO, Vieira ADS, Buriti FCA, do Nascimento JCF, de Melo MES, Bruno LM, Borges MF, Rocha CRC, Lopes ACS, Franco BDGM, Todorov SD (2015) Artisanal Coalho cheeses as source of beneficial Lactobacillus plantarum and Lactobacillus rhamnosus strains. Dairy Sci Technol 95:209-230

19. Buck BL (2006) Functional analysis of adhesión factors and signaling mechanisms in Lactobacillus acidophillus NCFM. A dissertation submitted to the Graduate Faculty of North Carolina State University in Microbiology. NC, USA

20. Ramiah K, van Reenen CA, Dicks LMT (2007) Expression of the mucus adhesion genes Mub and MapA, adhesion-like factor EF-Tu and bacteriocin gene plaA of Lactobacillus plantarum 423, monitored with real-time PCR. Int J Food Microbiol 116:405-409

21. Miyoshi Y, Okada S, Uchimura T, Satoh E (2006) A mucus adhesion promoting protein, MapA, mediates the adhesion of Lactobacillus reuteri to Caco-2 human intestinal epithelial cells. Biosci Biotechnol Biochem 70:1622-1628

22. Watanabe M, Kinoshita H, Nitta M, Yukishita R, Kawai Y, Kimura K, Taketomo N, Yamazaki Y, Tateno Y, Miura K, Horii A, Kitazawa $\mathrm{H}$, Saito T (2010) Identification of a new adhesin-like protein from Lactobacillus mucosae ME-340 with specific affinity to the human blood group A and B antigens. J Appl Microbiol 109:927-935

23. Lavilla-Lerma L, Pérez-Pulido R, Martínez-Bueno M, Maqueda M, Valdivia E (2013) Characterization of functional, safety, and gut survival related characteristics of Lactobacillus strains isolated from farmhouse goat's milk cheeses. Int J Food Microbiol 163:136-145

24. Juge N (2012) Microbial adhesins to gastrointestinal mucus. Trends Microbiol 20:30-39

25. Etzold S, Kober OI, MacKenzie DA, Tailford LE, Gunning P, Walshaw J, Hemmings AM, Juge N (2014) Structural basis for adaptation of lactobacilli to gastrointestinal mucus. Environ Microbiol 16:888-903

26. Savage DC (1992) Growth phase, cellular hydrophobicity and adhesion in vitro of lactobacilli colonizing the keratinizing gastric epithelium in the mouse. Appl Environ Microbiol 58:1992-1995

27. Vinderola G, Capellini B, Villarreal F, Suarez V, Quiberoni A, Reinheimer J (2008) Usefulness of a set of simple in vitro tests for the screening and identification of probiotic candidate strains for dairy use. LWT-Food Sci Technol 41:1678-1688

28. Zago M, Fornasari ME, Carminati D, Burns $\mathrm{P}$, Suàrez V, Vinderola G, Reinheimer J, Giraffa G (2011) Characterization and probiotic potential of Lactobacillus plantarum strains isolated from cheeses. Food Microbiol 28:1033-1040

29. Liserre AM, Re MI, Franco BDGM (2007) Microencapsulation of Bifidobacterium animalis subsp. lactis in modified alginate- chitosan beads and evaluation of survival in simulated gastrointestinal conditions. Food Biotechnol 21:1-16

30. Mandal S, Puniya AK, Singh K (2006) Effect of alginate concentrations on survival of microencapsulated Lactobacillus casei NCDC-298. Int Dairy J 16:1190-1195

31. Von Mollendorff JW (2008) Characterization of bacteriocins produced by lactic acid bacteria from fermented beverages and optimization of starter cultures. MSc Thesis (Microbiology), Stellenbosch University, Stellenbosch, Republic of South Africa

32. Todorov SD, Botes M, Guigas C, Schillinger U, Wiid I, Wachsman MB, Holzapfel WH, Dicks LMT (2008) Boza, a natural source of probiotic lactic acid bacteria. J Appl Microbiol 104:465-477

33. Brink M, Todorov SD, Martin JH, Senekal M, Dicks LMT (2006) The effect of prebiotics on production of antimicrobial compounds, resistance to growth at low $\mathrm{pH}$ and in the presence of bile, and adhesion of probiotic cells to intestinal mucus. J Appl Microbiol 100:813-820

34. Haller D, Colbus H, Ganzle MG, Scherenbacher P, Bode C, Hammes WP (2001) Metabolic and functional properties of lactic acid bacteria in the gastro-intestinal ecosystem: a comparative in vitro study between bacteria of intestinal and fermented food origin. Syst Appl Microbiol 24:218-226

35. Kleerebezem M, Boekhorst J, van Kranenburg R, Molenaar D, Kuipers OP, Leer R, Tarchini R, Peters SA, Sandbrink HM, Fiers MWEJ, Stiekema W, Lankhorst RMK, Bron PA, Hoffer SM, Groot MNN, Kerkhoven R, de Vries M, Ursing B, de Vos WM, Siezen RJ (2003) Competitive genome sequence of Lactobacillus plantarum WCFS1. Proceed Nat Acad Sci USA 100:1990-1995

36. Charteris WP, Kelly PM, Morelli L, Collins JK (1998) Development and application of an in vitro methodology to determine the transit tolerance of potentially probiotic Lactobacillus and Bifidobacterium species in the upper human gastrointestinal tract. J Appl Microbiol 84:759-768

37. Swagerty DL, Walling A, Klein RM (2002) Lactose intolerance. Amer Family Phys 65:1845-1850

38. Vizoso-Pinto MG, Franz CMAP, Schillinger U, Holzapfel WH (2006) Lactobacillus spp. with in vitro probiotic properties from human faeces and traditional fermented products. Int J Food Microbiol 109:205-214

39. De Smet I, Van Hoorde L, Vande Woestyne M, Cristianes H, Verstraete W (1995) Significance of bile salt hydrolytic activities of lactobacilli. J Appl Bacteriol 79:292-301

40. Jones ML, Martoni CJ, Prakash S (2012) Cholesterol lowering and inhibition of sterol absorption by Lactobacillus reuteri NCIMB 30242: a randomized controlled trial. Europ J Clin Nutr 66:1234-1241

41. Todorov SD, Furtado DN, Saad SMI, Tome E, Franco BDGM (2011) Potential beneficial properties of bacteriocin-producing lactic acid bacteria isolated from smoked salmon. J Appl Microbiol 110:971-986

42. Todorov SD, Botes M, Danova ST, Dicks LMT (2007) Probiotic properties of Lactococcus lactis subsp. lactis HV219, isolated from human vaginal secretions. J Appl Microbiol 103:629-639

43. Tuomola EM, Salminen SJ (1998) Adhesion of some probiotic and dairy Lactobacillus strains to Caco-2 cell cultures. Int J Food Microbiol 41:45-51

44. Todorov SD, Dicks LMT (2009) Bacteriocin production by Pediococcus pentosaceus isolated from marula (Scerocarya birrea). Int J Food Microbiol 132:117-126

45. Minahk CJ, Dupuy F, Morero RD (2004) Enhancement of antibiotic activity by sublethal concentrations of enterocin CRL35. J Antimicrob Chemother 53:240-246

46. Patrzykat A, Friedrich CL, Zhang LJ, Mendoza V, Hancock REW (2002) Sublethal concentrations of pleurocidin-derived antimicrobial peptides inhibit macromolecular synthesis in Escherichia coli. Antimicrob Agents Chemother 46:605-614 